Revista Iberoamericana, Vol. LXX, Núm. 207, Abril-Junio 2004, 565-578

\title{
LA CONCEPTUALIZACIÓN DE LA CIRCUNSTANCIA \\ EN EL PENSAMIENTO DE LEOPOLDO ZEA
}

\author{
POR \\ Francisco JAVIER HigUERo \\ Wayne State University
}

La producción ensayística de Leopoldo Zea se ha convertido en un ineludible punto de referencia de cualquier análisis en torno a los procesos creadores del pensamiento latinoamericano, a partir de la segunda mitad del siglo xx. La concepción de la filosofía ostentada por este escritor parte de unos presupuestos conceptuales entroncados en los raciocinios discursivos llevados a cabo por José Ortega y Gasset, al tiempo que reconoce la deuda intelectual procedente del magisterio intelectual de José Gaos y establece aproximaciones o distancias, según los casos, respecto a pensadores tan conocidos como Samuel Ramos, Augusto Salazar Bondy, Francisco Miró Quesada y Luis Villoro, entre otros que pudieran ser aludidos a este respecto. De lo expuesto por Ortega en Meditaciones del Quijote, Zea adquiere el concepto de la circunstancia, íntimamente unido al de la perspectiva, que le ayuda a superar, en cierto grado, el enfrentamiento existente entre teorías idealistas y posturas realistas. Las aportaciones filosóficas de Gaos ayudan a ir concretizando la circunstancia dentro de parámetros culturales latinoamericanos. Finalmente, las objeciones y reparos puestos por otros pensadores al proceder argumentativo de Zea servirán para que este ensayista vaya perfilando sus propios posicionamientos intelectuales, matizando dialécticamente las tesis por él defendidas. Las páginas que siguen tienen como finalidad estudiar el papel conceptual desempeñado por dicha circunstancia en los escritos de Zea, prestando atención al modo específico y concreto de raciocinar filosóficamente, adoptado por tal pensador.

\section{Delimitación FILOSÓfica DEL CONCEPTO DE CiRCUNSTANCiA}

Para precisar con rigor la procedencia intertextual del concepto de circunstancia, tal y como lo utiliza Zea, conviene remontarse a lo expresado explícitamente en Meditaciones del Quijote, en donde se advierte que el ser humano rinde el máximo de su capacidad cuando adquiere la plena conciencia de sus circunstancias, a través de las cuales se comunica con el universo. No obstante, conviene puntualizar que, para Ortega, dichas circunstancias en modo alguno representan una totalidad o conjunto inamovible, fijo y definitivo, propenso a ser apresado categóricamente, después de realizar una síntesis dialéctica, superadora de tesis y antítesis, tal y como la lleva a cabo G.W.F. Hegel en la Lógica. Acaso distanciándose de lo que posteriormente parece proponer el propio Zea, 
conviene no olvidar que el razonamiento seguido en Meditaciones del Quijote no responde a dialéctica alguna ni tampoco se interesa por aprisionar tranquilizadoramente a conjuntos absolutos. Dicho raciocinio argumentativo no se propone, pues, conseguir éxitos hermenéuticos en los que no queden cabos sueltos ya que, en modo alguno, se logra llegar a la meta deseada. Por otro lado, conviene prestar atención al hecho de que en tal escrito de Ortega se afirma, con contundencia, que no existen sino sólo partes en la realidad, yque el todo es la abstracción de las mismas, al tiempo que éste se ve precisado a necesitar de ellas. En efecto, cualquier modalidad de cultura se presenta parcialmente bajo la especie de la vida individual, de lo inmediato. Cuanto ha logrado reconocimiento ya sea como verdad, como belleza ejemplar, o como algo altamente valioso, nació un día de lo profundo de individuos concretos, no exentos de caprichos y limitaciones. En consecuencia, el ser del mundo es perspectiva, desmantelándose así cualquier intento totalizador, aunque fuera del signo dialéctico al modo propuesto por Hegel. Aparece aquí, por tanto, una contingencia perspectivista que se va debilitando progresivamente por la multiplicación de sus términos, siempre limitados en grado extremo. ${ }^{1}$

En Meditaciones del Quijote se advierte que es la circunstancia en donde se hallan las limitaciones y peculiaridades de cualquier perspectiva, siempre fragmentaria y nunca percibida como totalizante. Dicha perspectiva cambiante, según los casos, impide el asentamiento idealista en una totalidad fija, definitiva y determinada. Por tanto, el sujeto reflexionante que adopta una perspectiva determinada no se halla desencarnado ni tampoco sobre él se ha llevado a cabo una reducción fenomenológica como la propuesta en los primeros escritos de Edmund Husserl. La circunstancia no sólo contamina a ese sujeto, sino que llega a formar parte de él integrándose en su propio ser. En el escrito citado Ortega se pronuncia a favor de la inseparable unión intrínseca del yo y su respectiva circunstancia, la cual no debe ser entendida sólo de un modo espacial ni tampoco orgánico. De hecho, la circunstancia comprende tanto el mundo exterior como el interior y excluir a este último implica no tener en cuenta el sentido radical del yo, quien, dentro de su propia indigencia, precisa de una salvación consistente en la posesión de la circunstancia, urgida por la necesidad implacable de saber a qué atenerse respecto a ella. Dicha circunstancia posee un carácter real y se encuentra en manifiesta interdependencia con el yo, quien, en modo alguno, se agota en ser mero sujeto de vivencias intencionales de signo fenomenológico. Ahora bien, en Meditaciones del Quijote, el concepto de circunstancia se articula con el de perspectiva, aun en el caso de que aquélla quiera eludir a ésta. Es tal la relevancia que cobra la perspectiva en dicho escrito ensayístico, que a ella se le otorga un atributo consistente no en el conocimiento, ni en ningún aspecto suyo, sino en lo real, poseedor de una estructura propia y rigurosa, a la cual se precisa atenerse. La perspectiva se perfecciona por la multiplicación de sus términos y la exactitud con que se reacciona

\footnotetext{
${ }^{1}$ La apreciación crítica de la contingencia radical se encuentra en consonancia con corrientes de pensamiento contemporáneo, distante de abstracciones enajenadoras, tales como las ejemplificadas en la defensa del sujeto pensante llevada a cabo por René Descartes en The Discourse on Method and the Meditations, o la reivindicación del yo trascendental realizada por Immanuel Kant en Crítica de la razón pura, lo mismo que en la acogida al espíritu absoluto otorgada por Hegel en Fenomenología del espíritu.
} 
a cada uno de sus rangos. Para expresarlo de otra forma, hay una estructura de lo real, que sólo se presenta perspectivamente, necesitando integrarse desde múltiples términos o puntos de vista que reclaman reconocimiento de los propios límites manifestados, sobre todo, en la reacción por ellos suscitada. Siempre que se erige un punto de vista particular en punto de vista absoluto, en vez de situarlo en su justo lugar dentro de un entorno pluriperspectivista, se cae en el error de apropiarse inadecuadamente de la infinitud de todos los puntos de vista posibles, llegando hasta establecer un orden jerárquico entre ellos. El reconocimiento indigente de la propia circunstancia, desde la que se cobra conciencia de la perspectiva adoptada, siempre sometida a límites, se encuentra distante de cualquier tipo de absolutismo otorgado a un específico punto de vista concreto. Por consiguiente, ya se está en condiciones de poder afirmar que la perspectiva no es, de hecho, sino la condición de lo real y la posibilidad de acceso al entorno. ${ }^{2}$

En Meditaciones del Quijote el posicionamiento procedente de la perspectiva en modo alguno puede ser calificado de arbitrario, pues, como ha precisado con cierta contundencia Antonio Rodríguez Huéscar en La Innovación Metafísica de Ortega, tal postura no depende únicamente del yo, sino también y sobre todo del amplio abanico de posibilidades semánticas y estructurales abierto por la circunstancia. ${ }^{3} \mathrm{El}$ mundo cultural en el que se incluyen opiniones, creencias, ideas, instituciones, artefactos, instrumentos y todo tipo de actividades humanas, tratadas por Ortega en El hombre y la gente, forma parte de la circunstancia desde la que el yo cobra una perspectiva concreta. El punto de vista del yo depende en gran medida de su circunstancia, de la cual es, en último término, inseparable. De hecho, no existe un yo no circunstanciado y si cambian las perspectivas de éste se debe o bien a que se han modificado las circunstancias o han aparecido algunas nuevas, tal vez impredecibles. Si el yo creara la perspectiva, entonces la circunstancia se convertiría en algo secundario y accidental, no formando parte integrante de él. En tal caso pudiera causarse la impresión de que teorías filosóficas de signo idealista predominasen opresoramente sobre cualquier resquicio de realismo, quedando segregado éste a una irrelevancia casi total. Para decirlo de otra forma, siempre y cuando haya que contar con la circunstancia, el idealismo desencarnado no habrá logrado triunfar. Como contrapartida, no está de más constatar la imposibilidad de que la circunstancia llegue a cobrar un claro y distinto predominio absoluto, pues nunca deja de precisar del yo tanto como éste de ella. En cualquier caso, son las circunstancias concretas, consideradas como asentamientos de las correspondientes perspectivas, las que impiden la adquisición de absolutismos idealistas, convertidos éstos en atractivas metas semánticas. Por otro lado, resulta también cierto que ninguna circunstancia pudiera constituirse en morada de las perspectivas en cuestión sin las posiciones adoptadas y los puntos de vista adquiridos por el yo, nunca desencarnado y al cual se le tiene en cuenta una y otra vez a lo largo del raciocinio discursivo de Meditaciones del Quijote.

\footnotetext{
${ }^{2}$ El concepto de perspectiva en Meditaciones del Quijote no coincide con el que había sido explicado por Friedrich Nietzsche en La Gaya Ciencia. Según Ortega, la perspectiva acerca a la realidad. Sin embargo, para Nietzsche, la perspectiva equivale a la apariencia convencional, siendo una mera ilusión en muchos casos.

${ }^{3}$ Las implicaciones metafísicas involucradas en los conceptos de circunstancia y perspectiva han sido estudiadas por John W. Dixon en "Ortega and the Redefinition of Metaphysics".
} 


\section{REIVINDICACIÓN DE LA CIRCUNSTANCIA LATINOAMERICANA}

El pensamiento filosófico focalizado en la circunstancia y en la perspectiva se desarrolló a lo largo de la producción ensayística de Ortega e influyó explícitamente, sobre todo a través del magisterio intelectual ejercido por Gaos, en las argumentaciones que incisivamente esgrime Zea. En líneas generales se precisa afirmar, a este respecto, que desde el punto de vista de la legitimación filosófica, Gaos reelabora el concepto de circunstancia para adaptarlo a la realidad latinoamericana. Ha sido José Luis Abellán quien, en La idea de América y "Leopoldo Zea: hilo filosófico entre España y México,” ha destacado el papel inestimable de justificación histórica desempeñado por Gaos, quien constata la coherencia existencial evidenciada en el hecho de que -tras el fracaso de la Segunda República española- los ciudadanos exiliados se acogieran a la hospitalidad proporcionada por diversos países latinoamericanos. Para este pensador, España resulta ser la última colonia de sí misma, la última nación del común pasado imperial, que queda por hacerse independiente. Gaos afirma en Filosofía mexicana de nuestros días que España hace tiempo que quedó estancada en un inmovilismo casi absoluto; de aquí que nazcan en ella, de tiempo en tiempo, individuos cuya fuerte personalidad hace imposible su integración social, produciéndose entonces entre tales individuos y la sociedad, un reactivo de tal calibre que su precipitación provoca el salto a Latinoamérica, la cual se presenta así como la única posibilidad histórica de un futuro español. Para expresarlo en otros términos, las tierras latinoamericanas constituyen la única proyección posible de una historia de España que hace tiempo quedó periclitada en su propia tierra.

Partiendo del papel que juega Latinoamérica en relación a la tarea filosófica que desea llevar a cabo Gaos, este pensador se ve abocado a salvar la circunstancia correspondiente a su nueva adscripción cultural e histórica. ${ }^{4}$ Ahora bien, una vez asentado en México, dicho filósofo nunca logró trascender ni superar su condición de "transterrado" que, no obstante, le ayudó a comprender las raíces históricas de la circunstancia latinoamericana. Dentro de tales condicionamientos, el pensamiento de Ortega, del cual se encuentra imbuido Gaos, llega a Zea, ensayista que no tendrá reparo alguno en reconocer la imposibilidad de formulación histórica a no ser que se disponga de una filosofía considerada como expresión conceptual y teórica de la época en cuestión, convertida ésta en ineludible fondo circunstancial, propicio a servir de base a futuras construcciones culturales. No obstante, conviene tener en cuenta que Zea no es exiliado, como lo era Gaos, sino un ciudadano oriundo de México, aunque -por imperativo de su formación filosófica orteguiana- se encontraba obligado a salvar su circunstancia, si bien su condición de latinoamericano nativo situaba dicha circunstancia en una perspectiva muy distinta, aunque no tanto como para que no pudieran buscarse notas o características compatibles, entre las cuales, sin duda, sobresale el uso común de la misma lengua. En inmediata

\footnotetext{
${ }^{4}$ La propuesta encaminada a salvar la circunstancia proviene literalmente de la expresión lanzada con reverberaciones panfletarias en Meditaciones del Quijote por Ortega cuando afirma inequívocamente, "Yo soy yo y mi circunstancia y si no la salvo a ella no me salvo yo" (30).
} 
secuencia con esta apreciación crítica aparece otro rasgo no desdeñable que pudiera ser explicado de la siguiente forma: si Gaos se encontraba exiliado y, en cuanto tal, acaso pudiera ser percibido como un marginado respecto al país de origen, algo no muy distinto, aunque con ciertas connotaciones diferentes, le acaecía a Zea, que vivía en una nación marginada, en gran medida, de los presuntos centros álgidos de la producción filosófica mundial. Esa conciencia de filosofar desde la marginación va a nutrir el pensamiento de Zea, dotándole de especial interés, conforme lo ha evidenciado Adolfo Sánchez Vázquez en "Reflexiones sobre la obra de Leopoldo Zea”. A partir de dicha línea discursiva, Zea constata la unión entre España y Latinoamérica, procediendo a exponer los presupuestos que permitan construir realizaciones culturales, propensas a tener en cuenta circunstancias de marginación compartidas. Tal es, en gran parte, el raciocinio argumentativo que dicho pensador sigue en Discurso desde la marginación y la barbarie.

Al prestar la debida atención a la circunstancia sobresale el factor ideológico de una filosofía vinculada a condiciones y relaciones sociales, tal y como Zea lo pone de manifiesto tanto en El positivismo en México como en En torno a una filosofía americana. En dichos escritos ensayísticos, dicho pensador pone de relieve, de modo incisivo y verificable, el nexo existente entre la filosofía del orden establecido que encarnaba el positivismo en México y la dominación impuesta por el régimen porfirista. Este desenmascaramiento se encuentra en consonancia con la tarea llevada a cabo por Zea al proponerse desentrañar, de la mejor manera factible, una modalidad de raciocinio filosófico que se encuentra asentado en la realidad o circunstancia latinoamericana. Precisa Zea que lo que contribuye a calificar de latinoamericana a la filosofía no reside en la búsqueda de una esencia o ser fijo y definitivo, propio del ámbito histórico y cultural de Latinoamérica, pues esto no sería sino una extensión a nivel continental de la antropología mexicana que había postulado Samuel Ramos en El perfil del hombre y la cultura en México. ${ }^{5}$ De acuerdo con lo explícitamente advertido por Sánchez Vázquez en el mencionado artículo, la pretensión de Ramos de unir filosofía y circunstancia, al tiempo que se intenta construir un pensamiento nacional del ser mexicano, había quedado bloqueada al ignorar el entramado económico y social en que se inserta. Zea no se propone seguir esta vía muerta de la antropología de Ramos. Por otro lado, tampoco considera que lo latinoamericano radique en una originalidad a ultranza en el modo de filosofar. Lo que califica de latinoamericana a la filosofía estaría más bien en los problemas que vive el hombre latinoamericano y que afloran en su historia, encontrándose entre ellos el de la dependencia, no sólo la del pasado respecto a España, sino la actual ante el imperio norteamericano. En definitiva, aquello por lo que se interesa Zea, en sus escritos ensayísticos, es por la historia de una enajenación, no inherente a la presunta esencia del hombre latinoamericano, sino impuesta desde fuera por el mundo occidental. De aquí brota la necesidad de una liberación que pasa por la toma de conciencia del estado crónico de dependencia y de la posibilidad de superarla. Este aspecto inequívocamente liberador de la filosofía latinoamericana le aleja a ésta de la univocidad reduccionista de que adolece

\footnotetext{
${ }^{5}$ El abandono de cualquier tipo de esencialismo por parte de Zea posee también antecedentes intertextuales en el pensamiento de Ortega, quien en Historia como sistema reivindica que el hombre no tiene naturaleza, sino historia.
} 
gran parte del pensamiento occidental, cuyo punto de partida es la perspectiva adoptada desde una circunstancia a la que absolutiza, abstrayéndola en función de intereses ocultos o no suficientemente revelados, al tiempo que se intenta universalizarla, otorgándola una pretendida validez indiscutible. Tal proceder filosófico, con el que se muestra en desacuerdo Zea, se queda, con frecuencia, en una visión puramente contemplativa e intemporal de un mundo no circunstanciado y abierto solamente al dictamen procedente de una única y excluyente perspectiva. Podemos advertir que, en conformidad con lo reiterado sin disimulo alguno por Sánchez Vázquez, acaso el pensamiento de Zea, calificado con acierto y justicia de historicista, no se libre en su totalidad de cierta carga especulativa, sobre todo en la medida en que al situar al hombre latinoamericano -y con él a la filosofía- en el ámbito de circunstancias culturales y literarias, deja un tanto en la sombra las relaciones económicas y las contradicciones de clase. Esto explica que Zea potencie de un modo idealista el papel de la conciencia, como paso previo al proceso de liberación, sin tomar debidamente en cuenta que esa conciencia se adquiere también a lo largo del mismo proceso de liberación. Con todo, la filosofía postulada por Zea, al establecer conexiones entre ideas conceptuales y realidades circunstanciadas, cierra el paso a cualquier pretensión reduccionista, encaminada a especular sobre el presunto ser latinoamericano, teniendo en cuenta sólo la inmediatez local o en cualquier caso nacional, pero sin superar el entorno del subcontinente al que pertenece.

\section{Procedimiento historicista}

Si Zea no ha respondido explícitamente a las críticas formuladas por Sánchez Vázquez es posible que se deba al reconocimiento y respeto que le merecen los presupuestos ideológicos de ese pensador, aun sin estar de acuerdo con ellos. Sin embargo, con quienes Zea ha marcado pronunciadas distancias es con los planteamientos de escritores latinoamericanos tales como Salazar Bondy, Miró Quesada y Villoro, quienes habían objetado con seriedad su proceder filosófico de signo descaradamente historicista. En ¿Existe una filosofía de nuestra América? Salazar Bondy reitera su convencimiento de que la filosofía no puede concebirse sino como el efecto de una reflexión auténtica, de un pensar que sea filosofía simple y llanamente, pues lo latinoamericano vendrá por añadidura. Ya en esta postura o punto de partida se observa una notable diferencia respecto a lo postulado con rigor precisorio por Zea, como muy acertadamente lo ha advertido, en “La crítica ante la obra de Leopoldo Zea”, José Luis Gómez-Martínez. No debe olvidarse, a este respecto, que el raciocinio argumentativo utilizado por Zea va en busca del hombre concreto, de aquel que surge de la misma circunstancia de la que él forma parte, tratando de identificar sus problemas, al tiempo que se establece una reflexión filosófica en un intento de comprenderlos y de iniciar la búsqueda de soluciones. Del hombre mexicano, por afinidad de circunstancias, Zea se eleva al latinoamericano. Arranca pues de lo concreto pero, según va profundizando en la problemática original, desenmascara un conjunto de problemas basados precisamente en la humanidad de su temática. En La filosofía americana como filosofía sin más y Dependencia y liberación en la cultura latinoamericana, Zea descubre una constante en el enjuiciamiento de lo americano que enlaza a Ginés de Sepúlveda con Salazar Bondy. Si aquel opositor a las reivindicaciones 
de Bartolomé de Las Casas se atrevía a negar el alma a los indígenas, Salazar Bondy, a juicio de Zea, niega las manifestaciones propias del razonamiento específico de los latinoamericanos, es decir, su filosofía. Advierte este pensador en La filosofía americana como filosofía sin más:

Nuestro filosofar empieza así con una polémica sobre la esencia de lo humano y la relación que pudiera tener esta esencia con los raros habitantes del continente descubierto, conquistado y colonizado. En la polémica de Las Casas con Sepúlveda se inicia esa extraña filosofía que en el siglo XX se preguntará sobre si posee o no una filosofía. (13)

Las dificultades inherentes al raciocinio de Salazar Bondy, según Zea, residen en que al focalizar sus reflexiones en el hombre universal, abstracto, no se tengan en cuenta circunstancias concretas alejadas, con frecuencia, de los intereses esgrimidos por los centros de poder. En todo caso se importan a Latinoamérica interrogaciones que la ciencia y la tecnología imponen desde presupuestos ideológicos compartidos por la filosofía analítica, de procedencia anglosajona. Desde esa perspectiva occidental, Salazar Bondy advierte que la inautenticidad por él combatida, se enraíza en la condición histórica de países subdesarrollados, objeto de constatable dominio opresor. Es tal la condición deprimida de la economía latinoamericana la que contribuye a disminuir el dinamismo y la mínima fuerza para crear algo intelectualmente, susceptible de ser considerado original. Dichos planteamientos de Salazar Bondy le parecen a Zea, en gran medida, utópicos, ya que se hace depender a la posibilidad de la filosofía aunténticamente latinoamericana de cambios estructurales no llevados a cabo todavía. En La filosofía americana como filosofía sin más, Zea afirma que la autenticidad de la filosofía no podrá provenir de un supuesto desarrollo socioeconómico, sino del enfrentamiento contundente a problemas que se plantean y exigen soluciones radicales y humanistamente renovadoras. A este respecto, dicho pensador defiende una y otra vez, en Dialéctica de la conciencia americana que la libertad no procede de la cancelación del subdesarrollo, sino que es anterior a éste y, en último término, puede causar tal suspensión buscada. Al comentar este posicionamiento teórico de Zea, Solomon Lipp reconoce en Leopoldo Zea: From Mexicanidad to a Philosophy of History que la opresión o el subdesarrollo nunca han sido un impedimento decisivo que haya eliminado todo tipo de creaciones intelectuales.

En torno a la polémica suscitada por los posicionamientos encontrados de Zea y Salazar Bondy, Francisco Miró Quesada constata en Proyecto y realización del filosofar latinoamericano la existencia de esas dos aproximaciones al quehacer filosófico. Según el primero de estos acercamientos, con el que estaría de acuerdo Zea, tal quehacer consiste en filosofar sobre su propia realidad o circunstancia. La otra aproximación, promovida por Salazar Bondy, considera que es preciso asumir lo hecho por la filosofía europea, elevándose hasta su nivel. Tanto Miró Quesada en el mencionado escrito ensayístico, como Villoro en "Sobre el problema de la filosofía latinoamericana” parecen mostrarse más de acuerdo con lo defendido por Salazar Bondy que con los planteamiento de Zea. Miró Quesada y Villoro simpatizan y coquetean con presupuestos claves de la filosofía analítica, centrada en conceptos universales y exenta de contenidos explícitamente ideológicos. Estos pensadores reconocen que tal filosofía es propia de países desarrollados 
y opinan que mediante la adopción de sus raciocinios se puede contribuir a obtener, con diverso grado de aproximación, las metas conseguidas en el occidente europeo, equiparando dichos objetivos con lo genuinamente universal. Dentro de este contexto argumentativo, el filósofo debe cumplir una función auxiliar respecto al desarrollo armónico de las ciencias y su labor sería eficaz no sólo en el formulamiento preciso y riguroso, sino también en la clarificación de conceptos básicos que se encuentran en cualquier propuesta o teoría científica. Zea, por su parte, advierte que el deseo de seguir la moda de las corrientes europeas o estadounidenses conduce al espejismo de creer haber encontrado la filosofía por excelencia, sin percibir que con ello se cae, de hecho, en una renovada servidumbre, esta vez respecto a la técnica propia de los centros desarrollados. Dicho escritor que, con indiscutible honradez, considera las nuevas corrientes como legítimas formas de pensar, desenmascara, sin embargo, las proyecciones neocolonialistas que ellas encubren y se reafirma en su posición de que la filosofía es algo más que la ciencia rigurosa, algo más que la lógica capaz de deslindar con precisión lo que se proponga. La filosofía es también ideología y ética que se pregunta por el retraso de ciertos logros humanos en comparación con los altos resultados tecnocientíficos. En La filosofía americana como filosofía sin más, Zea concluye que se precisa de una filosofía propensa a favorecer la toma de conciencia de la propia condición humana dentro de su concreticidad personal y colectiva.

Villoro dice comprender el pensamiento de Zea, pero admite que no alcanza a ver su trascendencia y, quizás por ello mismo, considera sus propósitos una quimera utópica cuyo efecto más palpable acaso consista en frenar la marcha hacia el progreso del pueblo latinoamericano. Si se siguieran o implementaran los planteamientos de Zea, piensa Villoro que se reduciría enormemente la posibilidad de que lo calificado explícitamente como latinoamericano se encontrara en condiciones de llegar a influir en el pensamiento de determinados centros de dominio, cuya expansión resulta, de hecho, inevitable. Villoro no ostenta reparo alguno en pronunciarse explícitamente a favor de la filosofía analítica, hecha por especialistas para especialistas, tal y como se refleja en las discusiones académicas protagonizadas en el mundo industrializado. Este pensador se encuentra predispuesto a concluir que la producción filosófica de nivel profesional requiere de ciertas condiciones mínimas y no puede hacer acto de presencia hasta que éstas existan. La realización de tales requisitos presupone que la sociedad haya entrado en cierta etapa de desarrollo. Según Villoro, la presunta filosofía de Zea se limita a ser una expresión ideológica que sirve para tomar conciencia de los condicionamientos, orientaciones, proyectos y juicios evaluativos de grupos sociales o de determinadas colectividades políticas, desempeñando, en todo caso, una función cultural divulgadora. Tal menosprecio hacia el proceder de Zea recuerda el desdén y hasta la exclusión discriminatoria de que son objeto, en numerosas instituciones académicas anglosajonas, aquellos pensadores que no compartan la dedicación profesional hacia lo dictaminado e impuesto por lo promotores

\footnotetext{
${ }^{6}$ Resulta de hecho sumamente dificultoso, sino imposible, preocuparse por liberación alguna cuando el raciocinio discursivo se centra única y exclusivamente dentro de los parámetros de la filosofía analítica, la cual, según lo expresado por Javier Muguerza en Desde la perplejidad, empequeñece todo lo que toca.
} 
de la filosofía analítica. Miró Quesada no muestra un entusiasmo tan incondicional, como el de Villoro, hacia este tipo de filosofía y en Despertar y proyecto del filosofar latinoamericano se ve obligado a reconocer que, por ignorar los problemas de la acción humana, la filosofía analítica contribuye de manera indirecta a mantener el orden de poder implantado. ${ }^{6}$ Esta es precisamente también la opinión esgrimida por Evandro Agazzi en “¿Qué espera la comunidad filosófica internacional de la filosofía latinoamericana?”, estudio que denuncia el complejo de subdesarrollo que conduce a los intelectuales latinoamericanos a admitir implícitamente que su discurso cultural debería consistir precisamente en la imitación asimilatoria de modelos florecientes en centros industrializados de poder.

Miró Quesada advierte que cuando se defiende una filosofía universal y se identifica a ésta con procedimientos analíticos del pensar se razona bajo el supuesto de que la vigencia de una racionalidad implementada como consecuencia de la expansión de Occidente sobre el mundo entero. En tales circunstancias llega a considerarse que tal filosofía posee un carácter histórico indeleble. Según dicho pensador, la frenética expansión de Occidente ha extendido la racionalidad por él ejercida. En esta misma línea de pensamiento, que consiste en aceptar como un hecho inevitable la globalización de tal racionalidad, se sitúa Villoro, quien en El concepto de ideología no muestra reparo alguno en afirmar que el empeño por mantener, en un planeta ya unificado, centros de poder opuestos y crear barreras a través de elementos divisorios puede dar al traste con la marcha y el progreso hacia la unidad construida, en unos casos, y anhelada en otros. Al estudiar las diferencias filosóficas entre Villoro y Zea, Gómez-Martínez se ve precisado a puntualizar, en "La crítica ante la obra de Leopoldo Zea", que bajo la pretensión de objetividad analítica parecen repetirse fórmulas que tuvieron ya su momento de vigencia ideologizante a finales del siglo xIx, como por ejemplo la ostentada y defendida contundentemente por Domingo Sarmiento. Según Gómez-Martínez, la misma actitud que hizo posible el pensamiento de Sarmiento establece los parámetros que diferencian los fines implícitos en el quehacer filosófico de Zea, del de aquellos pensadores que se identifican con Villoro. Mientras Zea ve el hecho de haber querido imitar lo pensado en los centros de dominio como la causa directa de la situación actual de marginamiento y encuentra la posibilidad de superar la dependencia mediante una clara y distinta toma de conciencia de la propia circunstancia, Villoro da por sentado que el crecimiento expansivo de la civilización occidental desencadenó un proceso por el que dejaría de circunscribirse a un reducido espacio limitado. Sólo una cultura sin centro ni periferia puede aspirar a convertirse en una cultura universal. En El concepto de ideología, Villoro mantiene, a este respecto, que la pérdida del centro de la civilización occidental abrió el camino a la realización de una cultura unida en todo el planeta. ${ }^{7}$ Zea, por su parte, no muestra reparo alguno en constatar explícitamente la expansión de la cultura occidental. Este pensador parte del convencimiento de que la circunstancia latinoamericana se encuentra, en gran

\footnotetext{
${ }^{7}$ Aun enfrentándose a los planteamientos filosóficos de Zea, Villoro se ve precisado a reconocer que, al someterse al dominio de una cultura más general, las culturas particulares sufren una suerte variable entre dos extremos: o su destrucción o su asimilación a la nueva cultura. En la mayoría de los casos, pasan por un estado de enajenación y de desintegración; en ninguno, el paso a un nivel mayor de unificación en las culturas se dio sin abandonos ni desgarramientos.
} 
medida, sumergida dentro de dicha cultura e incluso llega a creer que los logros más significativos de la misma proceden en la actualidad de los anhelos poseídos por los pueblos marginados. No obstante, la civilización impuesta, según Zea, no significa pérdida de un centro, sino más bien lo contrario. No debe olvidarse que el proceso globalizador de la cultura de los países técnicamente desarrollados se encuentra basado en rígidas estructuras que permiten perpetuar la existencia de pueblos dominadores y pueblos dependientes de aquellos.

IV. EL PROYECTO DE LA PROPUESTA HUMANISTA

Advierte Zea, sin dejar lugar a duda alguna, que el logro por excelencia de la cultura europea ha sido su constante lucha por la igualdad de derechos y también por la libertad. Estos valores son aceptados hoy en día, mayoritariamente, por gran parte de las culturas. Pero dicho pensador se lamenta que tanto Europa como Estados Unidos, aun basando sus estructuras internas en dichos valores, se nieguen, de hecho, a reconocer la humanidad de los pueblos marginados. Mediante el cálculo frío de la ciencia y la técnica se impone el dominio del centro, al que se otorga todo tipo de derechos, mientras que se justifica y acepta como natural la existencia de la otra realidad en la que viven los marginados. Si Miró Quesada y Villoro desean la asimilación del progreso científico - del que hacen depender el desarrollo- y adoptan una forma de filosofar, la analítica, que ellos creen es la más apta para conseguir tales fines, Zea asimila de la cultura europea y estadounidense su deseo de autenticidad y piensa que sólo mediante ella se conseguirá que los pueblos dominadores acepten el común atributo de la humanidad, aplicada a todos, tanto a los colocados en los presuntos centros de poder como a los que se encuentran en la periferia o son marginados. Ningún pueblo podrá alcanzar la humanidad que, con todo derecho, le corresponde a no ser que se la reconozca también a los demás, independientemente del nivel tecnológico obtenido. No está de más subrayar a este respecto, que, debido a su fondo humanista, la filosofía esbozada por Zea consiste en un proyecto crítico de denuncia respecto a las condiciones de dependencia y dominación que han negado, de hecho, la humanidad a los ciudadanos de los pueblos latinoamericanos. La solución a tal estado de dominio aplastante no promueve un aislamiento reduccionista, sino que implica llegar a reconocer, con solidaridad, la humanidad compartida, en justicia, por todos. Para lograr tal objetivo se requiere, como condición previa, un ineludible esfuerzo dirigido a reivindicar prioritariamente la humanidad de aquellos pueblos a quienes el colonialismo europeo les negó la palabra propia.

En concreto, la reflexión fundamental esgrimida en los escritos de Zea se focaliza en la circunstancia de Latinoamérica, a la que intenta comprender y explicar, buscando simultáneamente proyectos de genuina liberación. Dicho pensador se halla convencido de que el camino conducente al verdadero conocimiento de la diferencia latinoamericana no resulta ser otro que el de una investigación seria y rigurosa sobre la llegada de las ideas europeas al subcontinente americano, lo mismo que acerca de la recepción y del desarrollo evolutivo por ellas seguidas en tal circunstancia. En "Leopoldo Zea o la pasión por el tránsito de la dependencia a la liberación”, Raúl Fornet-Betancourt advierte el esfuerzo realizado por Zea con el fin de llevar a cabo tal proyecto de investigación en escritos 
ensayísticos tales como El positivismo en México o Dos etapas del pensamiento en Hispanoamérica. Estudiando la historia de las ideas en Latinoamérica se ve confrontado dicho filósofo con la necesidad de conceptualizar con rigor precisorio la historia misma de los pueblos hispanoamericanos. Tal historia de las ideas pone de relieve la importación de categorías y soluciones civilizatorias que no correspondían a las circunstancias reales y que, por consiguiente, o bien se convertían en ineficaces proyectos intelectuales de naturaleza académica o eran instrumentalizadas por minorías ilustradas. De aquí procede pues, según Zea, la urgente necesidad de fomentar una toma de conciencia histórica que conduzca a asumir, sin complejos ni inhibiciones, la realidad latinoamericana. Para dicho pensador, tal toma de conciencia tiene que realizarse ejecutando una perspicaz reapropiación del propio pasado. Todo esto lleva consigo el reencuentro inevitable con la historia latinoamericana. Ahora bien, dentro de este contexto, conviene insistir en que la filosofía propuesta por Zea no se contenta con explicar la realidad consustancial y propia de Latinoamérica. Los esclarecedores intentos de este pensador se encuentran ya insertos en un proyecto de radical transformación histórica. Se precisa puntualizar, a este efecto, que Zea al focalizar su tarea en el pasado de pueblos marginados y oprimidos considera que semejante esfuerzo llega a constituir una característica propia que ha de ser asumida y no simplemente negada, ya que en ella reside, en gran parte, la condición de la posibilidad de apertura, por parte de Latinoamérica, a un futuro propio, emancipado de la inercia provocada por la imitación de modelos propios de otras épocas históricas o de circunstancias ajenas y alienadoras. Conforme decía dicho pensador en Dependencia y liberación en la cultura latinoamericana, son los modelos los que crean los paternalismos y las dictaduras que, con cierta frecuencia paradójica, se establecen en nombre de la libertad la cual, de hecho, es negada al establecer exclusivismos humillantes.

La interpretación de la historia llevada a cabo por Zea resulta proyectarse en una manifiesta denuncia y simultáneamente se convierte en anuncio de un futuro propuesto desde la autenticidad de la propia circunstancia, pero sin abandonar la posición que le corresponde a Latinoamérica en el mundo. A partir de ahí, este pensador intenta determinar lo más coherentemente posible las posibilidades concretas de tal circunstancia. Esta tarea filosófica se lleva a cabo desde más allá de la marginalidad colonial, que se intenta superar, pero también desde más acá de las utopías irresolubles y, en última instancia, radicalmente amortiguadoras de cambios inmediatos. Tal es la perspectiva que se abre en escritos ensayísticos de Zea tales como América como conciencia, América en la historia, Dialéctica de la conciencia americana y Filosofía de la historia americana. Fornet-Betancourt constata que una lectura del discurso argumentativo utilizado en dichos escritos pone de relieve el encuentro y la formulación consiguiente de una categoría conceptual inserta en la circunstancia de Latinoamérica y que resulta cobrar un papel fundamental para la recta comprensión del pensamiento de Zea. Esta categoría no es otra que la dependencia socioeconómica y cultural, convertida en el factor histórico determinante

\footnotetext{
${ }^{8}$ En Proyecto y realización del filosofar americano Miró Quesada afirma que Zea no sólo es el primer pensador en haber elaborado, de forma relevante, una filosofía de la historia latinoamericana, sino también resulta ser un escritor pionero, sobre todo en lo que se refiere a la utilización del humanismo como medio para desarrollar y construir una filosofía de la historia.

${ }^{9}$ Según se pone de relieve en numeroso escritos ensayísticos de Ortega, del ensimismamiento procede el origen y desarrollo de la cultura. Por otro lado, la producción filosófica de Zea evidencia
} 
de los obstáculos que han impedido en Latinoamérica la realización de genuinos proyectos orientados a satisfacer o eliminar las apremiantes necesidades de pueblos marginados. Asimismo conviene hacer notar que es en estos escritos en donde Zea radicaliza su crítica al imperialismo y a la dependencia colonial, poniéndose de manifiesto la profunda orientación humanista que inspira su filosofía. ${ }^{8}$ En "Leopoldo Zea: del positivismo en México a las ideas en Iberoamérica” José María Romero Baró señala, a este efecto, que lo circunstancial y hasta lo particular quedarían condenados al olvido si no se tuviese en cuenta un principio de universalidad inherente a lo considerado propiamente como humano y que vendría a constituirse en un postulado básico, en conformidad con el cual subyace algo comúnmente compartido tanto por individuos concretos como por las colectividades en que éstos se insertan. Se precisa no olvidar que es dentro de dichos individuos y grupos por ellos formados en donde puede residir la auténtica universalidad de valores determinados que cada cual encuentra en sí mismo. Para expresarlo de otra forma, desde su propio perfil el individuo concreto aporta líneas fundamentales que pueden contribuir tal vez a definir rasgos ineludibles de la humanidad, en general.

Conforme se ha advertido ya, tras requerir el marco histórico y circunstancial, determinante de toda filosofía, y tras postular inequívocamente la universalidad de cualquier aportación humana, Zea no tiene reparo alguno en proponer una vuelta del hombre sobre sí mismo con el fin de que éste tome conciencia de los modelos ajenos que sobre él pesan, empobreciéndole. De esta toma de conciencia puede surgir un genuino anhelo orientado a liberarse de toda subordinación enajenadora. ${ }^{9}$ Desde este punto de vista, la filosofía promueve la liberación desde dentro de uno mismo respecto a imposiciones ajenas y dependencias creadas. Ese yo circunstanciado puede, por tanto, contribuir directamente a la producción de cambios radicales que no lo enajenen de su propia e ineludible perspectiva sino que, por el contrario, contribuyan al crecimiento emancipatorio, precisado con urgencia por colectividades latinoamericanas. Son dichos pueblos y agrupaciones los que constituyen la circunstancia concreta desde la que argumenta Zea, al buscar un discurso alternativo a la dominación existente. Este discurso que se formula y articula desde la marginación y la barbarie tiene su eje decisivo en la alteridad latinoamericana o, mejor dicho, en su proyecto de realización histórica, integrado en una realidad diferente que reconoce al otro, en cuanto otro, para que éste a su vez escuche su palabra y la reconozca como palabra humana. En consecuencia, Zea se atreve a elaborar, en Discurso desde la marginación y la barbarie, una contundente propuesta de liberación que, desde la alteridad, busca tanto la comunicación universal como el reconocimiento mútuo, en base a la solidaridad igualitaria que debe existir entre múltiples y variadas colectividades culturales. ${ }^{10}$

que el ensimismamiento puede derivar muy bien en un ansia liberadora, inserta, a su vez, en diversas y múltiples manifestaciones pluriculturales.

${ }^{10}$ Zea se esfuerza, en Discurso desde la marginación y la barbarie, por evidenciar un incisivo y esclarecedor acercamiento entre circunstancias y condicionamientos culturales distintos, trazando argumentativamente numerosas conexiones históricas entre pueblos tan diferentes como pudieran ser el británico, el español y el ruso. 
A la hora de recapitular brevemente lo que precede, se precisa reiterar el asentamiento del concepto de circunstancia, tal y como lo utiliza Zea a lo largo de sus escritos ensayísticos, en el pensamiento de Ortega. Conforme se ha explicado, la circunstancia se encuentra integrada por opiniones, creencias, ideas, instituciones, artefactos, instrumentos y todo tipo de actividades humanas realizadas desde una perspectiva concreta. Gaos esclarece tal concepto, refiriéndose principalmente a Latinoamérica, desde donde reflexiona filosóficamente Zea, reconociendo como punto de partida de su raciocinio argumentativo un intolerable estado de dependencia que exige una bien merecida liberación. Ahora bien, el procedimiento reflexivo de este pensador en modo alguno puede ser tachado de simplificatorio, ya que en sus escritos aparece una profunda orientación humanista de carácter universal, en la que se tiene en cuenta una conciencia de los propios condicionamientos circunstanciales, desde una perspectiva que siempre es única y limitada, resistiéndose a ser absolutizada a través de medios coactivos o a imponerse contundentemente. Ahora bien, no debe pasar desapercibido que el discurso argumentativo de Zea acaso resulte vulnerable no sólo frente a las objeciones arrojadas sobre él por Sánchez Vázquez al explicitar que tal discurso no tiene suficientemente en cuenta las relaciones económicas y las contradicciones de clase, sino quizás también debido a una cierta tendencia esgrimida por ese razonamiento que tiende a la búsqueda de soluciones idealistas, acaso calificadas de utópicas. No debe olvidarse, a este respecto, que la solución dialéctica de signo conciliador, propuesta por Zea al asumir gran parte de los valores de la cultura occidental, aun teniendo en cuenta la circunstancia latinoamericana, tal vez resulte ser fácticamente irrealizable o, de hecho, conduzca a una disimulada pero muy eficaz eliminación de ésta. Es muy difícil que estos intentos conciliatorios puedan resistir los embates dirigidos desde planteamientos deconstructores, según los cuales la subversión de confrontaciones provenientes de dicotomías binarias no llega a eliminar ninguna de las partes enfrentadas. En cualquier caso, y a pesar de las objeciones arrojadas desde el pensamiento deconstructor, la producción ensayística de Zea no sólo constituye un acierto en lo que a la conceptualización de la circunstancia latinoamericana se refiere, sino también resulta ser un ejemplo de una filosofía de la liberación, encaminada a suprimir dependencias indebidas.

\section{BiBLIOGRAFÍA}

Abellán, José Luis. La idea de América. Origen y evolución. Madrid: Istmo, 1972. “Leopoldo Zea: hilo filosófico entre España y México”. Anthropos 89 (octubre, 1988): 48-51.

Agazzi, Evandro. “¿Qué espera la comunidad filosófica internacional de la filosofía latinoamericana?” Cuadernos Americanos 1/3 (1987): 163-78.

Descartes, René. The Discourse on Method and the Meditations. Baltimore: Penguin Books, 1971.

Dixon, John W.. "Ortega and the Redefinition of Metaphysics”. Cross Currents XXIX/ 3 (Fall 1979): 281-301.

Fornet-Betancourt, Raúl. “Leopoldo Zea o la pasión por el tránsito de la dependencia a la liberación”. Anthropos 89 (octubre, 1988): 51-4. 
Gaos, José. Filosofía mexicana de nuestros días. México: UNAM, 1954.

Gómez-Martínez, José Luis. “La crítica ante la obra de Leopoldo Zea”. Anthropos 89 (octubre, 1988): 36-48.

Hegel, G.W.F. Lógica. Madrid: Ed. R. Aguilera, 1971. Fenomenología del espíritu. México: Fondo de Cultura Económica, 1952.

Kant, Immanuel. Crítica de la razón pura. Madrid: Alfaguara, 1978.

Lipp, Solomon. Leopoldo Zea: From Mexicanidad to a Philosophy of History. Waterloo: Wilfrid Laurier University Press, 1980.

Miró Quesada, Francisco. Despertar y proyecto del filosofar latinoamericano. México: Fondo de Cultura Económica, 1974.

Proyecto y realización del filosofar americano. México: Fondo de Cultura Económica, 1981.

Muguerza, Javier. Desde la perplejidad. Madrid: Fondo de Cultura Económica, 1990.

Nietzsche, Friedrich. La Gaya Ciencia. Madrid: Akal, 2001.

Ortega y Gasset, José. Meditaciones del Quijote. Madrid: Revista de Occidente, 1975. El hombre y la gente. Madrid: Espasa Calpe, 1972. Historia como sistema. Madrid: Alianza, 1981.

Ramos, Samuel. El perfil del hombre y la cultura en México. Buenos Aires: Espasa Calpe, 1951.

Rodríguez Huéscar, Antonio. La Innovación Metafísica de Ortega. Crítica y superación del idealismo. Madrid: Ministerio de Educación y Ciencia, 1982.

Romero Baró, José María. "Leopoldo Zea: del positivismo en México a las ideas en Iberoamérica”. Anthropos 89 (octubre, 1988): 59-61.

Salazar Bondy, Augusto. ¿Existe una filosofía de nuestra América?. México: Siglo XXI, 1979.

Sánchez Vázquez, Adolfo. "Reflexiones sobre la obra de Leopoldo Zea”. Anthropos 89 (octubre, 1988): 34-6.

Villoro, Luis. El concepto de ideología y otros ensayos. México: Fondo de Cultura Económica , 1985.

“Sobre el problema de la filosofía latinoamericana”. Cuadernos Americanos 1/3 (1987): 86-104.

Zea, Leopoldo. El positivismo en México. Nacimiento, apogeo y decadencia. México: Fondo de Cultura Económica, 1968. En torno a una filosofía americana. México: El Colegio de México, 1945. Dos etapas del pensamiento en Hispanoamérica. México: El Colegio de México, 1949. América como conciencia. México: UNAM, 1983. América en la historia. México: Fondo de Cultura Económica, , 1957. La filosofía americana como filosofía sin más. México: Siglo XXI, 1986. Dependencia y liberación en la cultura latinoamericana. México: J. Mortiz, 1974. Dialéctica de la conciencia americana. México: Alianza, 1976.

Filosofía de la historia americana. México: Fondo de Cultura Económica, 1987. Discurso desde la marginación y la barbarie. Barcelona: Anthropos, 1988. 